\title{
The Application of Life Table Functions: A Demographic Study
}

\author{
Chinelo Mercy Igwenagu \\ Department of Industrial Mathematics/ Applied Statistics, \\ Enugu state University of Science and Technology, Nigeria.
}

\begin{abstract}
Life table is a key summary tool for assessing and comparing mortality conditions prevailing in populations. It is also a veritable tool for the study of mortality experience in a population. Hence, this paper has extended its application to infant survival pattern, using data on infant mortality collected from University of Nigeria Teaching hospital Enugu for a period of ten years; from 1998 to 2007. The application of the life table function was used to generate the periodic life table for the period under study, which made it possible to examine the mortality condition of the target population. The survival curve plotted follows the type 111 curve indicating situation in a population that has most of its mortality among the young. This calls for the attention of health officials to intensify their effort towards overcoming the challenges of infant mortality in Enugu State of Nigeria.
\end{abstract}

Keyword: Hospital, Infants, Life tables, Mortality, and Survival curve.

\section{Introduction}

Life table method has been widely employed in the study of mortality since it has distinct advantages over other measurements of mortality. Its conventional terms are generally recognized and are efficient medium of communication.[1]. The life table is a key summary tool for assessing and comparing mortality conditions prevailing in populations. Its construction requires reliable data on a population's mortality rates, by age and sex. The most reliable source of such data is a functioning vital registration system where all deaths are registered. Deaths at each age are related to the size of the population in that age group usually estimated from population censuses, or continuous registration of all births, deaths and migrations. The resulting age-sex-specific death rates are then used to calculate a life table. There are two type of life table construction and each has its peculiarity. The variations on the two types of life table; Cohort and periodic life tables are based on the nature of data used for construction [2]. In this paper, a period life table was constructed for the analysis. The main reason for this choice is that the data collected were recorded in years; from 1998 to 2007 and are therefore not in the same cohort. The periodic life table is capable of including ten years of data in one life table and generating meaningful statistical estimations from these observations even though the data are from different cohorts. The periodic life table is a mathematical model of the life history of a hypothetical cohort [3]. Over the years, the starting number of the hypothetical cohort, $l o$, is arbitrary in deterministic life tables, and is usually taken as one hundred thousand $(100,000)$, without a reason [4]. Since the value of this function is taken arbitrarily without reason, one can as well decide to change the value without any loss of information. This paper explores the possibility of using available data on infant mortality to estimate the survival function, following the view of [5].

\section{Methodology}

Using the data on infant mortality in University of Nigeria Teaching Hospital Enugu for a period of ten years; 1998 to 2007, the life table functions were generated. The data on infant mortality were as presented on table 1 below;

Table 1 Infant Mortality by Years

\begin{tabular}{|l|l|}
\hline Years & Infant mortality $\left(\mathrm{a}_{\mathrm{x}}\right)$ \\
\hline 1998 & 403 \\
\hline 1999 & 156 \\
\hline 2000 & 130 \\
\hline 2001 & 128 \\
\hline 2002 & 124 \\
\hline 2003 & 120 \\
\hline 2004 & 103 \\
\hline 2005 & 99 \\
\hline 2006 & 93 \\
\hline 2007 & 54 \\
\hline
\end{tabular}


Using the data on TABLE 1 above, the following life table functions were generated;

(1) $q_{x}$ : the probability that someone aged exactly $x$ will die before reaching age $(x+1)$

(2) $p_{x}$ : the probability that someone aged exactly $x$ will survive to age $(x+1)$

$$
p_{x}=1-q_{x}
$$

(3) $l_{x}$ : the number of people who survive to age $x$ note that this is based on a starting point of lo lives, here taken as 1000

$$
l_{x+1}=l_{x} *\left(1-q_{x}\right)=l_{x} * p_{x}
$$

(4) $d_{x}$ : the number of people who die at aged $x$ last birthday

$$
d_{x}=l_{x}-l_{x+1}=l_{x} *\left(1-p_{x}\right)=l_{x} * q_{x}
$$

(5) $L_{x}$ : the average number alive during any particular year

(6) $T_{x}$ is an intermediate value for calculating the life expectancy

(7) $e_{x}$ : is the average life expectancy of individual of age $\mathrm{x}$ in years

Table 2 Periodic Life Table of Infants Mortality From 1998-2007

\begin{tabular}{|l|l|l|l|l|l|l|l|l|}
\hline years & $\mathrm{a}_{\mathrm{x}}$ & $\mathrm{l}_{\mathrm{x}}$ & $\mathrm{d}_{\mathrm{x}}$ & $\mathrm{q}_{\mathrm{x}}$ & $\mathrm{L}_{\mathrm{x}}$ & $\mathrm{T}_{\mathrm{x}}$ & $\mathrm{e}_{\mathrm{x}}$ & $\log \left(\mathrm{l}_{\mathrm{x}}\right)$ \\
\hline 1998 & 403 & 1000 & 613 & 0.613 & 694 & 2936 & 2.936 & 3 \\
\hline 1999 & 156 & 387 & 64 & 0.165 & 355 & 2242 & 5.793 & 2.59 \\
\hline 2000 & 130 & 323 & 5 & 0.015 & 321 & 1887 & 5.842 & 2.51 \\
\hline 2001 & 128 & 318 & 10 & 0.031 & 313 & 1566 & 4.922 & 2.5 \\
\hline 2002 & 124 & 308 & 10 & 0.032 & 303 & 1253 & 4.071 & 2.49 \\
\hline 2003 & 120 & 298 & 42 & 0.141 & 277 & 950 & 3.192 & 2.47 \\
\hline 2004 & 103 & 256 & 10 & 0.039 & 251 & 673 & 2.631 & 2.41 \\
\hline 2005 & 99 & 246 & 15 & 0.061 & 239 & 422 & 1.722 & 2.39 \\
\hline 2006 & 93 & 231 & 97 & 0.42 & 183 & 183 & 0.792 & 2.36 \\
\hline 2007 & 54 & 134 & 0 & 0 & 0 & & & 2.13 \\
\hline
\end{tabular}

\subsection{Method of Computation}

In TABLE 2 above, the following methods apply; the first column is the number of years of the study. The second column is the total number of infants $\left(\mathrm{a}_{x}\right)$ observed each year. The third column $\left(l_{x}\right)$ is the number of surviving infants adjusted to a standard population size of 1000 . The values are calculated as the current $\mathrm{a}_{x}$ divided by the original population size, and then multiplied by 1000. For example, year 1999 is $(156 / 403) * 1000$ while year 2000 is $(130 / 403) * 1000$. The values are rounded to the nearest whole number. The number dying $\left(d_{x}\right)$ represents the change in population size from year $x$ to year $x+1$. The number dying during year 1998 is 1000 $387=613$. For year 1999 the number dying is $387-323=64$. The mortality rate $\left(q_{x}\right)$ is calculated by dividing the current year's $d_{x}$ by the current year's $l_{x}$. For year $1998,633 / 1000=0.613$. For year 1999 the mortality rate is $64 / 387=0.165$. The average number alive during any particular year $\left(L_{x}\right.$; should not be confused with the number surviving $\left.1_{x}\right)$ is calculated by adding together $1_{x}+l_{x+1}$ and dividing by 2 . Thus, for year 1998 the average number alive is $(1000+387) / 2=694$. For year 1999: $(387+323) / 2=355$. The seventh column $\left(T_{x}\right)$ is an intermediate value for calculating the life expectancy. It is calculated by cumulatively adding the $\mathrm{L}_{\mathrm{x}}$ values from the bottom up. Thus, for year 2006, $\mathrm{T}_{2006}=\mathrm{L}_{2007}+\mathrm{L}_{2006} \quad\left(\mathrm{~T}_{2006}=0+183=183\right)$. For year $2005, \mathrm{~T}_{2005}=\mathrm{L}_{2005}+\mathrm{L}_{2006}$ $\left(\mathrm{T}_{2005}=183+2397=422\right)$. The life expectancy $\left(e_{x}\right)$ is the average life expectancy of infants in years. It is calculated by dividing $\mathrm{T}_{\mathrm{x}}$ by $\mathrm{l}_{\mathrm{x}}$. For year 1998, the average infant is expected to live for only another 2.936 years (2936/1000); approximately 3 . If they survive the year 1999, their life expectancy is an additional 5.793 years (2242/387). The last column is used to calculate a survivorship curve. It is simply the log of the number surviving $\left(\log \left({ }_{1 \mathrm{x}}\right)\right)$. The graph for the above data is as shown in fig. 1 below.

$\log \left(l_{x}\right)$ 


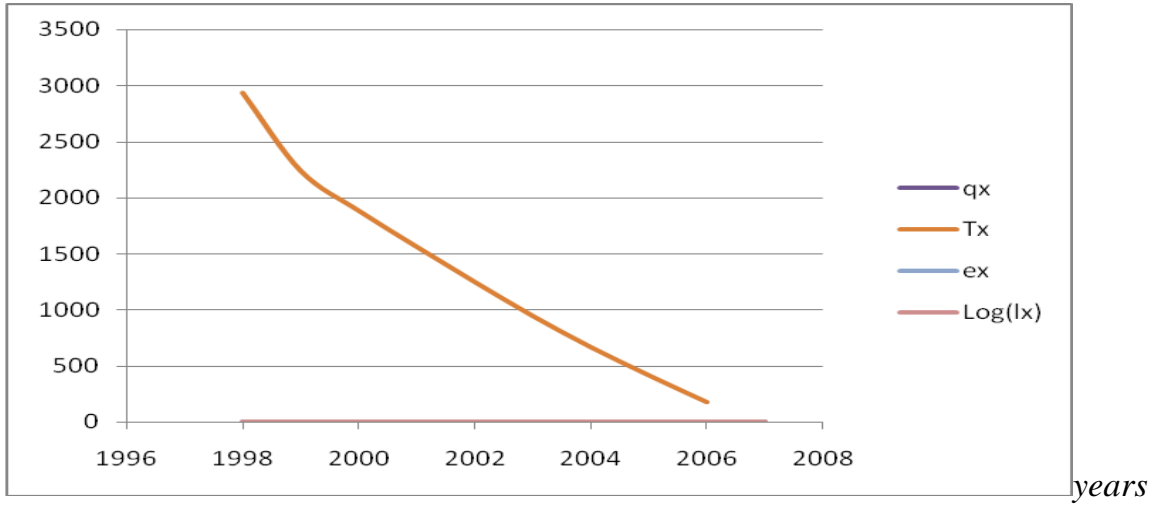

Figure1. The survivorship curve of infant in University of Nigeria teaching hospital Enugu from 1998 -2007

\section{ANALYSIS}

From the life table constructed in table 1 above, it can be observed that the mortality rate $q_{x}$ reduced drastically from 0.613 in 1998 to 0.165 in 1999. It continued decreasing and suddenly went up again to 0.420 in 2006. This could be attributed to either reduction in awareness campaign based on the assumption that people may have been aware of its consequences which led to reduction over the years or relaxation on the part of health officials based on the assumption that they have brought infant mortality under control. The expectation of life $e_{x}$ increased from approximately 3 years in 1998 to approximately 6 years in 1999 to 2000 . It could be said that once the infants get past the first few years, the ones that survive get to live for a longer time. The graph of $\log \left(l_{\mathrm{x}}\right)$ against the years, follow the type 111 chart in the survivorship curve. This resembles a population that has most of its mortality among the young. Therefore this serves as useful information to both parents and health bodies not to relent on the fight against infant mortality.

\section{References}

[1] Kaliaperumal V.G. , Venkataswamy Reddy. M, Channabasavanna S.M, Shivaji Rao and Joseph D.M. ( 1987)An Application of Life Table methods in the study of length of stay. Indian Journal of Psychiatry, 29(4), October 1987, 325-331

[2] Anousschkar van der meulen (2012) Life tables and Survival Analysis. Statistics Method, $2012 . \quad$ Statistics NetherlandsThe hagues/Heerlern Google Assessed on $8^{\text {th }}$ January,2014.

[3] Wei Zhang (1993) Survival Data Analysis-Life table methods. Synergic Resources Corporation NESUG '93 Proceedings, Google Assessed on $8^{\text {th }}$ January, 2014

[4]. Li, N. and S. Tuljapurkar(2014). The Probabilistic Life Table and Its Applications. Google Assessed on $8^{\text {th }}$ January,2014.

[5] Leonard K. Atuhaire (2011) Application of Current-Status Survival Analysis Methodology to Estimation of Age at First Sex: Uganda. The African Statistical Journal, 12, May 2011. 